\begin{tabular}{|l|l|}
\hline Postprint Version & 1.0 \\
Journal website & $\frac{\text { http://www.blackwell-synergy.com/doi/abs/10.1111/j.1532- }}{\text { 5415.2005.53006.x }}$ \\
\hline Pubmed link & $\begin{array}{l}\text { http://www.ncbi.nlm.nih.gov/entrez/query.fcgi?cmd=Retrieve\&db=pubmed } \\
\text { \&dopt=Abstract\&list uids=15667372\&query } \mathrm{hl}=6\end{array}$ \\
\hline DOI & \begin{tabular}{l}
$10.1111 / \mathrm{j} .1532-5415.2005 .53006 . \mathrm{x}$ \\
\hline
\end{tabular}
\end{tabular}

From the *Netherlands Institute for Health Services Research, Utrecht, the Netherlands; $\dagger$ Department of Nursing Home Medicine, Institute for Research in Extramural Medicine, the VU University Medical Center, Amsterdam, the Netherlands; and ‡ Department of Psychology,Utrecht University,Utrecht, the Netherlands.

This research project was financed by ZonMW, Netherlands Organization for Health Research and Development, Research Program "Elderly Care," Foundation Central Fund RVVZ, and the Province of Zeeland. Presented at the Third European Nursing Congress, October 2003, Amsterdam, the Netherlands.

Address correspondence to Julia C. M. van Weert, MA, NIVEL, PO Box 1568, 3500 BN Utrecht, the Netherlands. E-mail: j.vanweert@nivel.nl

\title{
Behavioral and Mood Effects of Snoezelen Integrated into 24-Hour Dementia Care
}

\author{
Julia C. M. vanWeert, MA,* Alexandra M. van Dulmen, PhD, * Peter M. M. \\ SpreeuwenberG, MA, ${ }^{*}$ Miel W. RibBe, MD, PhD, $\uparrow$ And Jozien M. Bensing, PhD*†
}

OBJECTIVES: To investigate the effectiveness of snoezelen, integrated in 24-hour daily care, on the behavior and mood of demented nursing home residents. DESIGN: Quasiexperimental pre- and posttest design. SETTING: Twelve psychogeriatric wards of six nursing homes, spread over different parts of the Netherlands. PARTICIPANTS: One hundred twenty-five patients with moderate to severe dementia and care dependency were included in the pretest and 128 in the posttest; 61 were completers (included in both preand posttest). INTERVENTION: Experimental subjects received an individual 24-hour snoezel program, based on family history taking and stimulus preference screening. Caregivers were trained, and (organizational) adaptations were made to fulfill the conditions for resident-oriented snoezel care. The control group received usual nursing home care. MEASUREMENTS: Observations were made on the wards using subscales of the Dutch Behavior Observation Scale for Psychogeriatric Inpatients, the Dutch version of the Cohen-Mansfield Agitation Inventory, and the Cornell Scale for Depression in Dementia. Independent assessors observed video recordings of morning care and rated residents' behavior and mood using INTERACT and FACE, respectively. RESULTS: Residents receiving snoezel care demonstrated a significant treatment effect with respect to their level of apathetic behavior, loss of decorum, rebellious behavior, aggressive behavior, and depression. During morning care, the experimental subjects showed significant changes in well-being (mood, happiness, enjoyment, sadness) and adaptive behavior (responding to speaking, relating to caregiver, normal-length sentences). CONCLUSION: Snoezel care particularly seems to have a positive effect on disturbing and withdrawn behavior. The results suggest that a 24-hour integrated snoezel program has a generalizing effect on the mood and behavior of demented residents. 
Dementia is a progressive, irreversible, neurological cognitive-impairment syndrome that affects about $6.1 \%$ of the population aged 65 and older. ${ }^{1}$ Once people are institutionalized, behavioral problems occur in up to $97 \%$ of cases and often reduce individuals' quality of life. ${ }^{2}$ In the view of the Dialectical Framework for dementia care,$^{3-5}$ dementia caregivers can do much to promote nursing home residents' quality of life. The central thesis is that the dementia process arises from an interaction between neurological impairment and social psychological processes (e.g., the interaction between caregivers and dementia patients). Certain kinds of malignant caregiver behavior, damaging to those who have dementia (malignant social psychology), and positive caregiver behavior, that make for well-being (positive person work) have been distinguished. ${ }^{3-5}$ Seventeen indicators of malignant social psychology, such as infantilization, stigmatization, and ignoring, and 12 indicators of positive person work, such as recognition, validation, and stimulation of the senses, have been identified. ${ }^{3-5}$

Snoezelen (Snoezelen is the registered trademark of Rompa, Chesterfield, England), or Multi-Sensory Stimulation (MSS), is a widely used and accepted approach to nursing home residents suffering dementia and seems to fit the premises of the Dialectical Framework. ${ }^{6}$ It was developed in the Netherlands but is becoming more popular in Great Britain and the United States. ${ }^{7}$ Snoezelen can be defined as an approach that actively stimulates the senses using light, sound, smell, and taste. ${ }^{8}$ The application of snoezelen requires a resident-oriented attitude, knowledge, and skills, allowing caregivers to incorporate personal circumstances such as lifestyle, preferences, desires, and cultural diversity to achieve or maintain a state of well-being. Therefore, snoezelen matches the concept of "patient-centeredness." The caregivers do not restrict themselves to the "resident's complaint" but orient themselves to the "resident with a complaint." care is to maintain personhood in the face of failing mental powers by showing empathy and gaining knowledge of the individual's personal history, personality, and needs. The required resident-oriented attitude to apply snoezelen includes the different types of interaction described in the Dialectical Framework as positive person work. ${ }^{3-5,8}$

Although several studies have been conducted to investigate the effectiveness of snoezelen, and the majority of them reported within-session positive effects, many lack a comparison between treatment and control groups. ${ }^{10}$ Only two randomized clinical trials of high quality are available, both evaluating the effect of snoezelen sessions in a special room. ${ }^{11}$ In these trials, positive immediate outcomes were found, particularly on apathetic behavior, but carryover and longerterm effects of snoezelen were not evident. ${ }^{11-14}$ This suggests that caregivers in daily contact with those with dementia should implement a continuous and ongoing program. ${ }^{11,15}$ Accordingly, the present study addresses the implementation of snoezelen as a person-centered 24-hour approach to care delivered by certified nursing assistants (CNAs) and integrating multisensory stimuli throughout the day.

The aim of the study was to investigate the effect of integrated snoezelen on behavior and mood of nursing home residents suffering from dementia. In particular, it was hypothesized that the intervention would lead to measurable changes in

- well-being: more happiness/contentment, more enjoyment, better mood

- adaptive behavior: more attentive and responsive in relation to the environment, more personal initiative, better relationship to caregiver

- maladaptive behavior: less antisocial behavior, apathetic behavior, loss of decorum, loss of consciousness, rebellious behavior, restless behavior, disoriented behavior, anxious behavior, agitation, aggression, and depression ${ }^{6,710,12-17}$

\section{METHODS}

A quasiexperimental pre- and posttest design was used. The study was performed in 12 psychogeriatric wards at six Dutch nursing homes. Each nursing home designated an experimental and a control ward. The six experimental wards implemented snoezelen in 24-hour care. Usual care continued in the six control wards. The implementation period lasted 18 months per ward between January 2001 and February 2003. Measurements were performed at baseline and after 18 months. 


\section{SAMPLE}

\section{Nursing Homes}

Six nursing homes in different parts of the Netherlands out of 19 potentially eligible sites were selected for the study. Dutch nursing homes are comparable with skilled nursing facilities in the United States. There are separate wards for patients with Alzheimer's disease. ${ }^{18}$

Interviews with staff members revealed whether the eligible nursing homes met the following inclusion criteria:

Snoezelen not yet implemented in the daily care of their residents

Presence of two comparable (population of residents, composition of nursing staff, care model used, level of attention and assistance) units with at least 15 residents that met the inclusion criteria for residents (assuming one-third nonresponse) and at least 10CNAs

Willingness to create the conditions to implement snoezelen in the daily care of the experimental ward

No snoezelen training during the study period or implementation of elements from the snoezel intervention on the control ward

Presence of some basic, practical conditions (e.g., a comfortable residents' chair for arm-hand massage)

No substantial organizational changes (e.g., removal, reorganization) during the study period Commitment to these criteria was laid out in a cooperative agreement.

The six nursing homes had a mean number of 194 residents (range 122-280) and 21 residents per ward (range 15-32). On average, staff-client ratio was 0.15 CNA per resident (range 0.14-0.16). In all nursing homes, CNAs consistently cared for the same residents every day. By selecting an experimental and a control ward from the same nursing home, the control wards were comparable with the experimental wards in terms of capacity, staff-client ratio, system of resident allocation, service types, care plans used, and level of assistance.

Randomization took place at the ward level. In four nursing homes, the wards were randomized by having an independent person draw lots from a sealed container. Two wards were assigned to the experimental group based on practical considerations (e.g., the presence of a room that could be used as a snoezelroom by other disciplines such as activity therapists). This decision was taken after careful assessment of other differences between the experimental and the control ward that might prejudice treatment comparisons (e.g., population, motivation of nursing staff, working atmosphere) to exclude selection and confounding biases.

\section{SUBJECTS}

\section{Residents}

To establish the effectiveness of snoezelen, a sample size of 120 residents ( 60 treatments, 60 controls) was required (power $=0.80, \alpha=0.05$, effect size $=0.50$ ). To be eligible for the trial, residents had to meet the following criteria

Moderate to severe dementia according to the Diagnostic and Statistical Manual of Mental Disorders, Third Edition, Revised, diagnosed by a physician ${ }^{19}$

Moderate to severe nursing care dependency, measured using the Care Dependency Scale for demented inpatients, an assessment instrument for use in psychogeriatric nursing homes. ${ }^{20-22}$ The degree of care dependency is assessed on a 5-point Likert-scale. A total sum score with a theoretical range from 15 to 75 can be computed, the higher the score, the less the dependency on nursing care. The internal consistency of the scale was high $(\alpha=0.93)$.

Absence of an additional psychiatric diagnosis (e.g., schizophrenia and other psychotic disorders)

Hearing and vision completely or partially unimpaired

Not bedridden

The ward staff selected a minimum of 15 residents who fulfilled the above criteria. About 1 month before the measurements, the legal guardians of the selected residents were informed by mail of the nature and the content of the study. They were asked to sign an informed consent form to allow video recording of the morning care for research purposes and the use of medical background characteristics. Guardians were informed about their right to withdraw at any time during the study. 


\section{Certified Nursing Assistants}

Every resident included wasmatched to aCNA, who had to be familiar with the resident. The majority of nursing staff members recruited for the study $(81.4 \%)$ worked in rotation shifts. Temporary staff, students, and CNAs only working at night were not eligible. The CNAs participated in the training program and observation sessions as part of their regular employment duties. Consent for their participation was obtained from the director of nursing. Every matched "couple" (resident- CNA) was videotaped once in the pretest and once in the posttest (when still on the ward) during morning care, using a hand-held camera. Twelve CNAs (seven in the pretest and five in the posttest) were videotaped twice because there were more residents than CNAs. When the level of intellectual capacity of the resident allowed verbal communication, the CNA informed the resident about the video recordings and asked permission. The CNAs and the research assistant were instructed to stop the video recording when they noticed negative reactions of the resident. Immediately after morning care, the CNAs were given the opportunity to disclose their feelings about the video recording. Although, in general, they experienced some stress in advance, the majority reported afterward that stress did not really affect their behavior and that the video reflected the normal situation. Despite the obvious fact that they were being observed, the CNAs and residents adapted to the presence of the observer, as previously reported. ${ }^{23,24}$

Thirty-seven CNAs of 117 were lost to follow-up, mainly because they changed jobs (19 in the experimental group and 18 in the control group); new CNAs replaced them. To be able to apply the snoezelen method, the new CNAs received training on the job and attended the followup meetings. The experimental and control group CNAs did not differ significantly in background characteristics. At baseline, $92.2 \%$ were female, and they had an average age of 34.9. Mean work experience was 7.6 years. On average, they worked 29.1 hours a week.

\section{Coping with Loss to Follow-Up}

To make sure that at least 60 residents could be included in each condition at posttest, the experimental wards were instructed to apply snoezelen care to all (new) residents who fulfilled the inclusion criteria. Consequently, a second cohort of subjects could be recruited to replace the dropouts from the first cohort of residents. Three months before the posttest, the same informed consent procedure was followed to obtain proxy consent from legal guardians of new eligible residents. Once the new care model (snoezelen in 24-hour care) was successfully implemented, the snoezelen program was supposed to be effective at the residents' level within 3 months, ${ }^{8}$ although the posttest was planned 18 months after the pretest, because 15 months was considered to be the minimum time needed for successful implementation of the new care model. ${ }^{25,26}$ This time was required to effect a change from task-oriented care to resident-oriented care and to effect changes at the organizational level, such as investments in snoezel materials and adaptation of daily schedules, activities, and procedures (e.g., no longer waking up residents who prefer to sleep late, no hurry to be ready with the morning care before the coffee break). ${ }^{26}$

\section{INTERVENTION}

Figure 1 gives a summary of the intervention and measurements. Details of the intervention have been described elsewhere. ${ }^{26}$

A qualified and experienced professional trainer of the Bernardus Expertise Center/Fontis, a nursing home with a connected training center specializing in snoezelen, trained the CNAs in snoezelen. Inhouse training included four weekly 4-hour sessions (16 hours total) and homework. The main objectives were to motivate team members and improve caregiver knowledge and practical skills with regard to resident-oriented care (e.g., attitude toward verbal and nonverbal communication) and snoezelen (e.g., how to take a family history, review specific behavior problems, observe sensory preferences, adapt care plans, and apply sensory stimulation in daily care). An extensive manual of snoezelen was available with specific instructions, methodology, observation forms, and examples on the integration of snoezelen into 24-hour care. At the end of the course, trainees received a certificate. Eighty caregivers attended the training program, 59 of whom were CNAs and six head nurses. The other participants (not included in the measurements) were activity therapists (n510), nutrition assistants (n52), a care manager (n51), a clerical worker (n51), and a student nurse (n51). Thus, almost complete teams were trained. Compliance with the training sessions was $92.5 \%$. 


\section{[ FIGURE 1 ]}

After the training, the CNAs took a detailed history of the matched residents' life and preferences by interviewing family members. Then, stimulus preference screening was arranged during 10 weekly 1hour sessions. The residents were offered various sensory stimuli (tactual, visual, auditory, olfactory, gustatory) to find out which they enjoyed most. Their reactions were observed and carefully registered.

Next, the CNAs wrote an individual snoezel plan based on life history, stimulus preference screening, and multidisciplinary conferences. The snoezel plans described the residents' specific behaviors and how to react to these behaviors (e.g., "Anxiety: Mrs. X is anxious when she goes to bed. Approach: sit down at the bedside, stroke her cheek, hold her hand. Then she will sleep soon'"). The snoezel plan was translated into the residents' snoezel care plan, to integrate the required approach into activities of daily living (e.g., how to wake up, whether the resident was capable of choosing own clothes, whether perfume or makeup could be used, how (eye) contact could be made, whether the resident liked to be touched affectively, whether music or aroma therapy could be used, which snoezel activities could be offered in the living room). During (multidisciplinary) consultations, the snoezel plans were evaluated and, if necessary, adapted to residents' changes in response or condition.

Each experimental ward set up a study group, usually comprising three CNAs, the head nurse, and an activity therapist or coordinator in sensory stimulation. The aim of the study group was to evaluate the implementation process structurally and to make adaptations where necessary.

The caregivers were offered three in-house follow-up meetings (10 hours total) under the guidance of the same professional trainer. The aim of these supervision meetings was to support the implementation of snoezelen in daily care by discussing the observations, evaluating the snoezel care plans, and providing feedback and video exercises. In addition, two general meetings, attended by three representatives per nursing home (e.g., head nurses, care managers), supported the implementation of snoezelen at the organizational level. Depending on the bottlenecks mentioned by the executive staff, implementation problems on the experimental wards were discussed.

\section{OUTCOME MEASURES}

The effectiveness of snoezelen was studied by observing residents on the wards and video recordings of morning care. The observations on the wards were intended to give insight into the overall (generalized) behavior of the residents during the previous 2 weeks. The video recordings enabled detailed observation of the residents' behavior during a well-defined care moment (within sessions). Morning care was videotaped because it is given on every ward in every nursing home and allows an unbiased comparison between treatment and control groups (individual attention with vs without snoezelen).

\section{Assessment of Behavior in the Ward Environment}

Matched CNAs conducted observation of residents on the ward using the most reliable, valid, and sensitive observation scales available in Dutch. ${ }^{27}$ Ratings covered the 2 weeks preceding the administration of the scales. Unless otherwise stated, the internal consistency of the data was sufficient to good. Details on psychometric properties are available upon request from the first author.

\section{CNA-Assessed Behavior}

Parts of the Dutch Behavior Observation Scale for Psychogeriatric In-patients (BIP) were used to measure the behavior of residents. ${ }^{27,28}$ The BIP is an extensive psychogeriatric behavior observation scale for institutionalized psychogeriatric people. The scale contains 82 four-point scale items divided over 14 independent subscales. ${ }^{28,29}$ The CNAs filled out the BIP completely, although only eight of the 14 subscales were selected as outcome measurements (nonsocial behavior, apathetic behavior, distorted consciousness, loss of decorum, anxious behavior, rebellious behavior, restless behavior, and disoriented behavior). The CNAs were not informed about selected subscales. In accordance with the manual, two CNAs completed the BIP together to maximize interrater reliability and to avoid observer bias. The subscale "memory disorders" (seven items) was used as a background 
characteristic/confounder. Disoriented behavior was excluded from analysis due to low Cronbach alpha (a50.47; 5 items). ${ }^{30}$

\section{Agitation}

CNAs completed the Cohen-Mansfield Agitation Inventory (Dutch version) (CMAI-D) to measure agitation. ${ }^{27,31-34}$ The CMAI is a caregivers' rating questionnaire consisting of 29 agitated behaviors, each rated on a 7-point frequency scale, ranging from never to several times an hour. The scale covers three syndromes of agitation: aggressive behavior, physically nonaggressive behavior, and verbally agitated behavior. ${ }^{31}$ In accordance with the manual, factor analysis was performed to control for the factor structure. ${ }^{32}$ The results confirmed earlier findings on the factor structure of the CMAI in a nursing home setting. ${ }^{33,34}$ Details are available from the first author.

\section{Depression}

The Cornell Scale for Depression in Dementia (Dutch version) (CSDD-D), designed for assessing depression in dementia patients, was used to measure depressive symptoms (mood-related signs, behavioral disturbance, physical signs, and cyclic functions). ${ }^{35,36}$ Each of the 15 items was rated on a scale from absent, to mild, to severe, to unable to evaluate.

\section{Video Assessment of Behavior During Morning Care}

Two independent observers rated the video observations of the residents during morning care. They were both university graduates, one in psychology and one in social sciences, and had worked as CNAs in the past. Training consisted of explaining the use of the scale, rating the same patients, and discussing discrepancies. The original guidelines were followed to minimize observer bias and reactivity. ${ }^{37}$ After 3 weeks of training, the "real" observations started. A technician randomly converted the videotapes to digital videodiscs, which one of the observers assessed. They were blinded as to whether the resident was in the experimental or control group. The observer watched a video recording twice before scoring to ensure a reliable assessment. The average duration of the videotaped morning care was 20.3 minutes.

\section{Observer-Assessed Behavior}

The video recordings were observed using the measuring device INTERACT, which was specifically designed to measure the effects of snoezelen on demented elderly. ${ }^{13,14,37,38}$ The scale includes 22 items about mood (4 items), speech (5 items), relating to other people (4 items), relating to the environment (4 items), need for prompting (1 item), and stimulation level (4 items), using a 5-point Likertscale, ranging from not at all to nearly all the time, to reflect behavior during morning care. Positive and negative behaviors of demented older people are identified. Eight study-specific items, based on the observation form of Bernardus Expertise Center/Fontis and literature, ${ }^{8,39,40}$ extended the INTERACT; two items were added to the relating to person domain and six to the stimulation level domain (Table 1). Six INTERACT items were excluded from analysis because of low interobserver reliability (Pearson $r<0.60$ ).

\section{[ TABLE 1 ]}

\section{Mood}

Individuals' mood was measured using three face diagrams (FACE) with different mouth shapes, which are considered universal symbols for happy, neutral, and sad affects. ${ }^{41-43}$ The observers were asked to rate the patient using a sad face if a frown predominated, a neutral face if the expression was neutral, and a happy face if a smile predominated.

\section{Reliability of the Video Observations}

Interrater reliability checks on the observational measures were conducted during observer training. The final interobserver reliability was calculated for 25 of 250 video recordings $(10 \%){ }^{44}$ Interrater reliability (mean Pearson $r$ ) of the 24 selected INTERACT items was 0.83 (range 0.68-0.99); for the FACE it was 0.84 . 


\section{Interviews}

After 15 months, the head nurses of the control wards were interviewed to find out whether the control wards refrained from snoezelen during the study period, conforming to the cooperative agreement. The results revealed that on three control wards, some CNAs started to apply parts of the snoezel methodology in the daily care (e.g., music, aroma), but no one integrated these parts in an individual, residentcentered approach, nor did anyone integrate them structurally. Because these are considered important conditions for snoezelen to be effective, no serious contamination risk was present on the control wards.

\section{Data Analysis}

All instruments were reviewed immediately after completion so that CNAs could be contacted about missing data. The amount of missing data for BIP, CMAI-D, and CSDDD was therefore negligible. Data resulting from video analysis were complete.

Descriptive statistics were obtained on the demographic characteristics of subjects in pretest and posttest and in the experimental and control groups. Differences in these variables were examined using chi-square tests or $t$ tests (Table 2).

As new residents were substituted for dropouts, multilevel analysis, performed using MLwiNsoftware (Multilevel Models Project Institute of Education, London, United Kingdom), was used for analyzing the data. A mixed model of multilevel analysis for repeated measurements was chosen, which takes into account all available data in an adequate way: the paired samples of completers (included in pre- and posttest) as well as the unpaired premeasurement or postmeasurement data of noncompleters (included in pre- or posttest). ${ }^{45,46}$ Two levels of analysis were distinguished: measurement and resident. The correlated measurements of completers are controlled for by modeling the covariance between the pre- and postmeasurement at the resident level.

To compare the rate of change across the two groups, the mean pretest/posttest differences in the experimental group were tested against the mean pretest/posttest differences in the control group.

The following characteristics were selected as relevant covariates in adjusted analysis to correct for differences in the residents' conditions and background characteristics: care dependency, memory impairment, age, duration of nursing home admission, and sex. ${ }^{19,20,25,27,47}$

The number of wards was too small to compare subgroups of nursing homes or to take similarity between wards into account.

\section{[ TABLE 2 ]}

\section{RESULTS}

\section{Response}

Figure 2 presents the study flow diagram.

Before the pretest, 155 legal guardians were asked to give written informed consent; 25 refused (11 in the experimental group and 14 in the control group). The main reason was objection to videotaping. No significant differences were obtained on age and sex between participants and refusers. Four cases (three in pretest and one in posttest) were excluded from the final analysis because information on background variables was missing. Because of residents' refusal, three video recordings of experimental subjects were missing. As they received the snoezel program, the ward observations were still used. From the 125 residents analyzed in the pretest, 61 "completers" could also be included in the posttest. Two of them had missing values in pretest or posttest. Their data were analyzed unpaired, similar to the data of "noncompleters." Sixty-eight "newly included residents" (noncompleters) entered the study group. The majority of legal guardians (43 of 47) of newly eligible experimental subjects gave informed consent, as a result of which the sample size increased from 64 at pretest (analyzed 62) to 66 at posttest (analyzed 66). In the control group, the sample size decreased from 64 at pretest (analyzed 63) to 63 at posttest (analyzed 62). 


\section{[ FIGURE 2 ]}

\section{Background Characteristics}

Table 2 summarizes the demographic characteristics for subjects at baseline.

The table shows that the experimental and control groups were to a large extent comparable on background characteristics. At baseline, there were no significant differences between the experimental and control groups.

\section{Outcomes}

Table 3 provides the adjusted estimated means (95\% confidence interval) and the change scores from the experimental group and the control group on the observed behaviors. On all measures, positive change scores indicate a change in favor of the experimental group.

A significant treatment effect was obtained for apathetic behavior, loss of decorum, rebellious behavior, aggressive behavior, and depressive behavior.

The effects of snoezelen during morning care are presented in Table 1. On measures representing positive feelings or adaptive behavior (e.g., happy/content, enjoying self, normal-length sentences), negative change scores indicate a change in favor of the experimental group. On measures representing maladaptive, negative behavior (e.g., restless, bored/inactive, verbal anger), positive change scores indicate a change in favor of the treatments.

Significant treatment effects were seen in the following nine INTERACT outcome measures: tearful/sad, happy/ content, talked with normal-length sentences, related well, enjoying self, bored/inactive, responding to speech, negativism/ complaining, and reluctance. The scores on FACE also showed a significant effect in favor of the experimental group. Restlessness and verbal anger improved marginally $(P<.100)$.

\section{DISCUSSION}

The results of this study support the effectiveness of snoezelen in dementia care. Residents receiving a snoezel approach, integrated into 24-hour daily care, demonstrated significantly more improvements with respect to their level of apathetic behavior, loss of decorum, rebellious behavior, aggressive behavior, and depression than the control group, who received usual care. During morning care, residents receiving the snoezel program showed more happiness and enjoyment, related better to the CNA, were more responsive to speaking, and talked more frequently with normallength sentences than the control group. They were also in a better mood and showed less sadness, bored and inactive behavior, negativism, and reluctance.

Although occasions have been reported in which participants had temporary behavioral deterioration or severe behavioral problems, which brought a definite stop to snoezel sessions, in the present study, no participants dropped out for that reason. ${ }^{10}$ Nor were there any other negative findings or side effects. An explanation might be that, in the present study, contrary to most of the other studies, a stimulus-preference screening was part of the intervention. This allowed staff to expose the participants selectively to the stimuli that they found more pleasurable and more suitable to their condition, which is recommended to help prevent or minimize behavioral problems within the snoezelen context. ${ }^{10}$ The within-session improvements found during morning care are consistent with positive findings obtained in earlier, less-rigorous studies (e.g., weak control conditions, limited number of sessions and use of descriptive data). ${ }^{6,7}$

Much of the literature on snoezelen demonstrates a wide range of positive outcomes, but there is little evidence of generalization. ${ }^{17}$ Four studies were found showing that the immediate postsession effects were more favorable than those of control conditions, ${ }^{10}$ yet longer-term, generalized effects of snoezelen were only reported in two of six studies, and these studies did not meet the criteria for high methodological quality. ${ }^{11}$ The overall improvement of behavior on the ward, found in the present study, seems to be an indication of the generalized effects of integrated snoezel

\section{[ TABLE 3 ]}


care. As expected, snoezelen influenced disturbing behaviors such as physical aggression and rebellion and withdrawn behaviors such as apathy or depression. A treatment effect was also found on loss of decorum, which has never been reported before. The increased attention of CNAs to the residents' preferences for their personal appearance, which is part of the integrated snoezel program, but not of the snoezel sessions in a special room described in earlier studies, might explain this. There was no generalized improvement of antisocial behavior, restless behavior, anxious behavior, loss of consciousness, verbal aggression, or physically nonaggressive behavior. Behaviors falling in the speech domain did not change either. Snoezelen is possibly less likely to affect these domains. Negative symptoms such as apathy and loss of decorum are perhaps amenable to treatment, whereas more complex behaviors such as agitation, restlessness, and anxiety or more cognitive competences such as speech seem to be more difficult to influence. ${ }^{48}$

The actual effective ingredient(s) of the snoezelen intervention still remain indeterminate. The combination of individualized, person-centered care and a 24-hour comprehensive care plan integrating multisensory stimulation might contribute to the success, although additional scientific research is needed to gain more insight into the underlying mechanisms.

Some methodological considerations need attention. Although the multilevel model takes into account the data of completers (included in pre- and posttest) and noncompleters (included in pre- or posttest), there might be conflicting findings in the patterns of deterioration and improvement in both groups. Subgroup analyses were conducted with regard to the variables that showed significant changes. There was no improvement in the control groups for completers or noncompleters. The experimental groups showed improvement or, within the subgroup of completers, no or small changes from pre- to posttest, with less deterioration in the experimental group than in the control group (BIP4 loss of decorum: experimental group $=+1.11$, effect size $=0.29$; control group $=+2.13$, effect size $=$ 0.82 ; responding to speaking: experimental group $=-0.48$, effect size $=0.37$; control group $=-1.00$, effect size $=0.71$ ).

Another potential limitation was the unblinded observations on the ward by CNAs. Whether participation in the study influenced the judgment of CNAs has been investigated by asking an independent CNA from another ward for a second opinion on the BIP subscales CMAI-D and CSDD$\mathrm{D}$ for $15 \%$ of the residents. ${ }^{25}$ No indications were found that the judgment of the first CNA assessor deviated systematically from the assessment of the independent CNA assessor. In the present study, CNAs completed five (hidden) BIP subscales that were not selected as outcome measurements, but effects were only found on selected subscales. In addition, the video observations were blinded and did not contradict the observations on the wards. Therefore, no sufficient bias is assumed.

The aim of using video recordings of the morning care was to provide supplementary data to the observations on the ward with the advantage of blinded assessment. The limitation to morning care may create measurement bias. In future studies, the video observations should be extended to other care moments.

The posttest was limited to one measurement. Future research should consider the measurement of outcome measures at different times to strengthen the results. Measurement intervals are also recommended to investigate the effectiveness of snoezelen at an individual level, to find out whether some residents benefit more from the snoezelen intervention than others.

The results need to be interpreted with caution because the experimental group appeared to show more behavioral problems at baseline than the control group, although the disordinal interactions still account for convincing results. There is no clear explanation for these differences in baseline scores. There might have been unexpected selection bias (e.g., the experimental wards might have been more eager to have their most difficult residents included). In future research, this might be prevented by selecting participants by the research team (e.g., after a period of participating observations), by randomizing the wards after the pretest, or by selecting residents on their main behavior problem (e.g., to focus on aggression or depression).

Finally, the INTERACT scale does not give sum scores, and the item-by-item analysis increases the risk of a falsepositive result (type I error). ${ }^{38}$ Although no contradictions were found in the results, future studies should develop a scale consisting of multiitem subscales measuring the same domains. At the beginning of this study, such measurement was not available. 


\section{ACKNOWLEDGMENTS}

The authors would like to thank the residents, their legal guardians, the CNAs, and the staff for their commitment to the study and Barry Emons for the discount on snoezel materials. The willingness of Bernardus Expertise Center/ Fontis and in particular Jan Peter (teacher) to perform the intervention in our study and support the implementation on the wards was greatly appreciated.

\section{TABLES AND FIGURES}

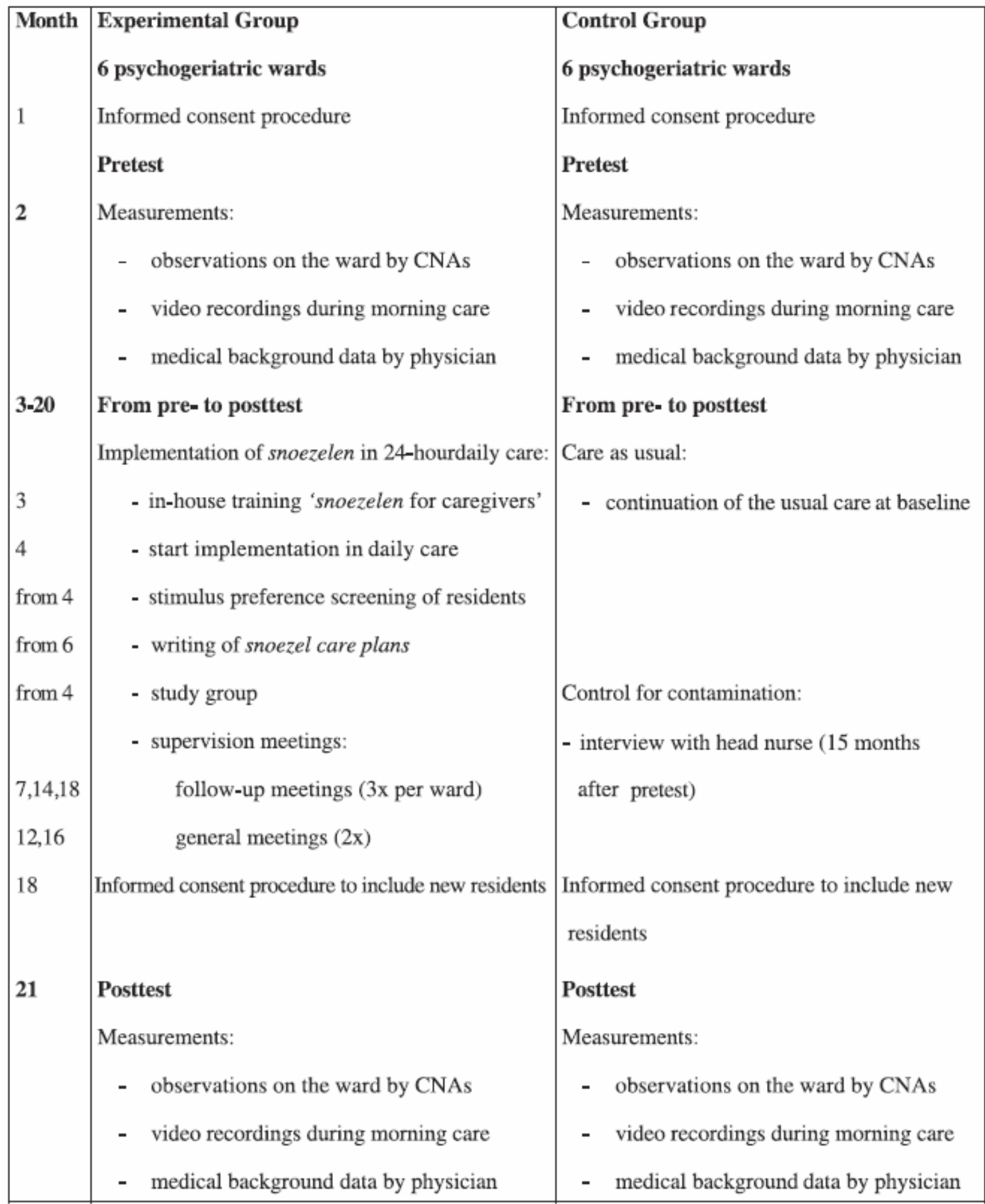

\section{Figure 1. Design of the study. CNA = Certified Nursing Assistant.}


J.C.M. van Weert, A.M. van Dulmen, P.M.M. Spreeuwenberg, M.W. Ribbe, J.M. Bensing Behavioral and mood effects of snoezelen integrated into 24-hour dementia care.

JAGS: Journal American of the Geriatrics Society: jrg. 50, 2005, nr. 1, p. 24-33

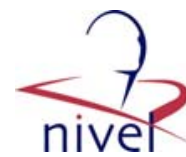

\begin{tabular}{|c|c|c|c|c|c|c|c|c|}
\hline \multirow[b]{3}{*}{ Outcome Measure } & \multicolumn{3}{|c|}{ Experimental Group } & \multicolumn{3}{|c|}{ Control Group } & \multirow{3}{*}{$\begin{array}{l}\text { Change } \\
\text { score* }\end{array}$} & \multirow{3}{*}{$\begin{array}{c}\chi^{2} \\
(d f=1)\end{array}$} \\
\hline & Pretest & Posttest & \multirow[b]{2}{*}{ Change } & Pretest & Posttest & \multirow[b]{2}{*}{ Change } & & \\
\hline & \multicolumn{2}{|c|}{ Mean $^{\dagger} \pm$ SE } & & \multicolumn{2}{|c|}{$\operatorname{Mean}^{\dagger} \pm \mathrm{SE}$} & & & \\
\hline \multirow{2}{*}{\multicolumn{9}{|c|}{$\begin{array}{l}\text { INTERACT (range 1-5) } \\
\text { Mood }\end{array}$}} \\
\hline & & & & & & & & \\
\hline Tearful/sad & $1.52 \pm 0.1$ & $1.29 \pm 0.1$ & 0.23 & $1.16 \pm 0.1$ & $1.54 \pm 0.1$ & $-0.39^{\ddagger}$ & $0.62^{\S}$ & 6.74 \\
\hline Happy/content & $2.74 \pm 0.2$ & $3.47 \pm 0.2$ & $-0.73^{\|}$ & $3.07 \pm 0.2$ & $2.63 \pm 0.2$ & 0.44 & $-1.17^{\|}$ & 13.82 \\
\hline Fearful/anxious & $1.60 \pm 0.1$ & $1.32 \pm 0.1$ & $-0.28^{\ddagger}$ & $1.40 \pm 0.1$ & $1.28 \pm 0.1$ & 0.12 & 0.16 & 0.70 \\
\hline \multicolumn{9}{|l|}{ Speech } \\
\hline Talked spontaneously & $2.45 \pm 0.2$ & $2.64 \pm 0.2$ & -0.20 & $2.42 \pm 0.2$ & $2.57 \pm 0.2$ & -0.14 & -0.06 & 0.04 \\
\hline Recalled memories & $1.22 \pm 0.1$ & $1.27 \pm 0.1$ & -0.04 & $1.26 \pm 0.1$ & $1.30 \pm 0.1$ & -0.03 & -0.01 & 0.01 \\
\hline Spoke clearly & $2.54 \pm 0.2$ & $2.65 \pm 0.2$ & -0.11 & $2.69 \pm 0.2$ & $2.86 \pm 0.2$ & -0.17 & 0.06 & 0.04 \\
\hline Spoke sensibly & $2.51 \pm 0.2$ & $2.86 \pm 0.2$ & -0.36 & $2.75 \pm 0.2$ & $2.61 \pm 0.2$ & 0.14 & -0.49 & 2.59 \\
\hline Normal-length sentences & $2.27 \pm 0.2$ & $2.83 \pm 0.1$ & $-0.56^{\S}$ & $2.58 \pm 0.2$ & $2.52 \pm 0.1$ & 0.06 & $-0.62^{\ddagger}$ & 4.46 \\
\hline \multicolumn{9}{|l|}{ Relating to person } \\
\hline Appropriate eye contact & $2.53 \pm 0.1$ & $2.98 \pm 0.1$ & $-0.45^{\S}$ & $2.50 \pm 0.1$ & $2.87 \pm 0.1$ & $-0.37^{\S}$ & -0.08 & 0.10 \\
\hline Related well & $3.40 \pm 0.1$ & $3.87 \pm 0.1$ & $-0.47^{\S}$ & $3.64 \pm 0.1$ & $3.35 \pm 0.1$ & 0.28 & $-0.75^{\ddagger}$ & 7.06 \\
\hline S: Listened to voice/noise & $4.25 \pm 0.1$ & $4.20 \pm 0.1$ & 0.05 & $4.30 \pm 0.1$ & $4.00 \pm 0.1$ & 0.30 & -0.25 & 1.13 \\
\hline S: Responded to speaking & $3.79 \pm 0.1$ & $3.54 \pm 0.1$ & 0.23 & $4.06 \pm 0.1$ & $3.24 \pm 0.1$ & $0.83^{\|}$ & $-0.60^{\ddagger}$ & 5.40 \\
\hline \multicolumn{9}{|l|}{ Relating to environment } \\
\hline Tracked observable stimuli & $2.78 \pm 0.1$ & $3.03 \pm 0.2$ & -0.26 & $3.31 \pm 0.1$ & $3.23 \pm 0.2$ & 0.08 & -0.34 & 2.06 \\
\hline $\begin{array}{l}\text { Touched objects/equipment } \\
\text { Need for prompting }\end{array}$ & $2.26 \pm 0.1$ & $2.20 \pm 0.1$ & 0.06 & $2.45 \pm 0.1$ & $2.16 \pm 0.1$ & 0.29 & -0.23 & 0.85 \\
\hline Own initiative & $1.94 \pm 0.1$ & $1.80 \pm 0.1$ & 0.14 & $1.87 \pm 0.1$ & $1.84 \pm 0.1$ & 0.03 & 0.12 & 0.25 \\
\hline \multicolumn{9}{|l|}{ Stimulation level } \\
\hline Restless & $1.67 \pm 0.1$ & $1.46 \pm 0.1$ & 0.21 & $1.47 \pm 0.1$ & $1.67 \pm 0.1$ & -0.19 & 0.40 & 2.70 \\
\hline Enjoying self, pleasure & $2.32 \pm 0.2$ & $3.17 \pm 0.2$ & $-0.84 \|$ & $2.54 \pm 0.2$ & $2.43 \pm 0.2$ & 0.10 & $-0.84^{\S}$ & 9.77 \\
\hline Bored, inactive & $2.33 \pm 0.2$ & $1.69 \pm 0.2$ & $0.64^{\S}$ & $2.05 \pm 0.2$ & $2.25 \pm 0.2$ & -0.20 & $0.85^{\S}$ & 7.21 \\
\hline S: Alert & $3.76 \pm 0.1$ & $3.74 \pm 0.2$ & 0.02 & $3.99 \pm 0.1$ & $3.69 \pm 0.2$ & 0.30 & -0.28 & 1.07 \\
\hline S: Verbal anger & $1.30 \pm 0.1$ & $1.07 \pm 0.1$ & 0.23 & $1.18 \pm 0.1$ & $1.26 \pm 0.1$ & -0.07 & 0.30 & 3.02 \\
\hline S: Aggressive & $1.25 \pm 0.1$ & $1.05 \pm 0.1$ & 0.19 & $1.11 \pm 0.1$ & $1.13 \pm 0.1$ & -0.02 & 0.21 & 2.10 \\
\hline S: Negativism, complaining & $1.85 \pm 0.1$ & $1.48 \pm 0.1$ & $0.37^{\ddagger}$ & $1.32 \pm 0.1$ & $1.65 \pm 0.1$ & -0.33 & $0.71^{\S}$ & 8.12 \\
\hline S: Reluctance & $1.43 \pm 0.1$ & $1.11 \pm 0.1$ & $0.32^{\ddagger}$ & $1.24 \pm 0.1$ & $1.38 \pm 0.1$ & -0.14 & $0.46^{\ddagger}$ & 5.59 \\
\hline $\begin{array}{l}\text { S: Repetitious mannerism } \\
\text { Face (range 1-3) }\end{array}$ & $1.42 \pm 0.1$ & $1.55 \pm 0.1$ & -0.13 & $1.40 \pm 0.1$ & $1.30 \pm 0.1$ & 0.11 & -0.24 & 0.92 \\
\hline Mood & $2.10 \pm 0.1$ & $2.49 \pm 0.1$ & $-0.39 \|$ & $2.17 \pm 0.1$ & $2.16 \pm 0.1$ & 0.11 & $-0.40^{\S}$ & 7.72 \\
\hline
\end{tabular}

* A significant change score means that the pre/post change in the experimental group was significantly different from the pre/post change in the control group. ${ }^{\dagger}$ Estimated mean score (multilevel analysis).

$\mathrm{SE}=$ standard error; $\mathrm{S}=$ study-specific additional item; $\chi^{2}=$ chi-square; $\mathrm{df}=$ degrees of freedom.

${ }^{\ddagger} P<.05:{ }^{\circledR} P<.01:{ }^{\|} P<.001$. 
Table 2. Background Characteristics at Baseline by Treatment Group

\begin{tabular}{|c|c|c|}
\hline Resident Characteristic & $\begin{array}{l}\text { Experimental } \\
\quad(n=62)\end{array}$ & $\begin{array}{l}\text { Control } \\
(n=63)\end{array}$ \\
\hline Female, n (\%) & $49(79.0)$ & $52(82.5)$ \\
\hline Age, mean $\pm S D$ & $84.0 \pm 8.6$ & $82.6 \pm 8.2$ \\
\hline $\begin{array}{l}\text { Duration of illness, years, } \\
\text { mean } \pm S D\end{array}$ & $5.6 \pm 2.7$ & $6.1 \pm 3.5$ \\
\hline $\begin{array}{l}\text { Residing in nursing home, } \\
\text { years, mean } \pm \text { SD }\end{array}$ & $3.1 \pm 2.5$ & $2.6(2.5)$ \\
\hline $\begin{array}{l}\text { Care Dependency Scale score } \\
\text { mean } \pm \text { SD (range } 15-75)^{*}\end{array}$ & $27.4 \pm 11.7$ & $29.5 \pm 11.2$ \\
\hline $\begin{array}{l}\text { Memory impairment, } \\
\text { mean } \pm \mathrm{SD}^{\dagger}\end{array}$ & $14.5 \pm 3.1$ & $13.4 \pm 4.0$ \\
\hline \multicolumn{3}{|l|}{ Diagnosis, n (\%) } \\
\hline Alzheimer's disease & $35(56.5)$ & $34(54.0)$ \\
\hline Vascular dementia & $13(21.0)$ & $5(7.9)$ \\
\hline $\begin{array}{l}\text { Combined Alzheimer's } \\
\text { disease and vascular } \\
\text { dementia }\end{array}$ & $10(16.1)$ & $16(25.4)$ \\
\hline Other dementia & $4(6.5)$ & $8(12.7)$ \\
\hline \multicolumn{3}{|l|}{ Predominant features, $\mathrm{n}(\%)$} \\
\hline With delirium & $0(0.0)$ & $0(0.0)$ \\
\hline With delusions & $10(16.1)$ & $12(19.0)$ \\
\hline With depressed mood & $8(12.9)$ & $9(14.3)$ \\
\hline With anxiety & $11(17.7)$ & $7(11.1)$ \\
\hline With primary insomnia & $6(9.7)$ & $6(9.5)$ \\
\hline Uncomplicated & $27(43.5)$ & $29(46.0)$ \\
\hline \multicolumn{3}{|l|}{ Cognitive disturbances, n (\%) } \\
\hline Aphasia & $3(4.8)$ & $5(7.9)$ \\
\hline Apraxia & $13(21.0)$ & $10(15.9)$ \\
\hline Agnosia & $31(50.0)$ & $28(44.4)$ \\
\hline None of these disturbances & $3(4.8)$ & $4(6.3)$ \\
\hline Unknown & $12(19.4)$ & $16(25.4)$ \\
\hline
\end{tabular}

Note: No significant differences in baseline characteristics were found between the experimental group and the control group.

* High score indicates least impairment.

${ }^{\dagger}$ Dutch Behavior Observation Scale for Psychogeriatric In-patients (range 0-21, low score indicates least impairment).

$\mathrm{SD}=$ standard deviation. 
Assessed for eligibility $(n=155)$

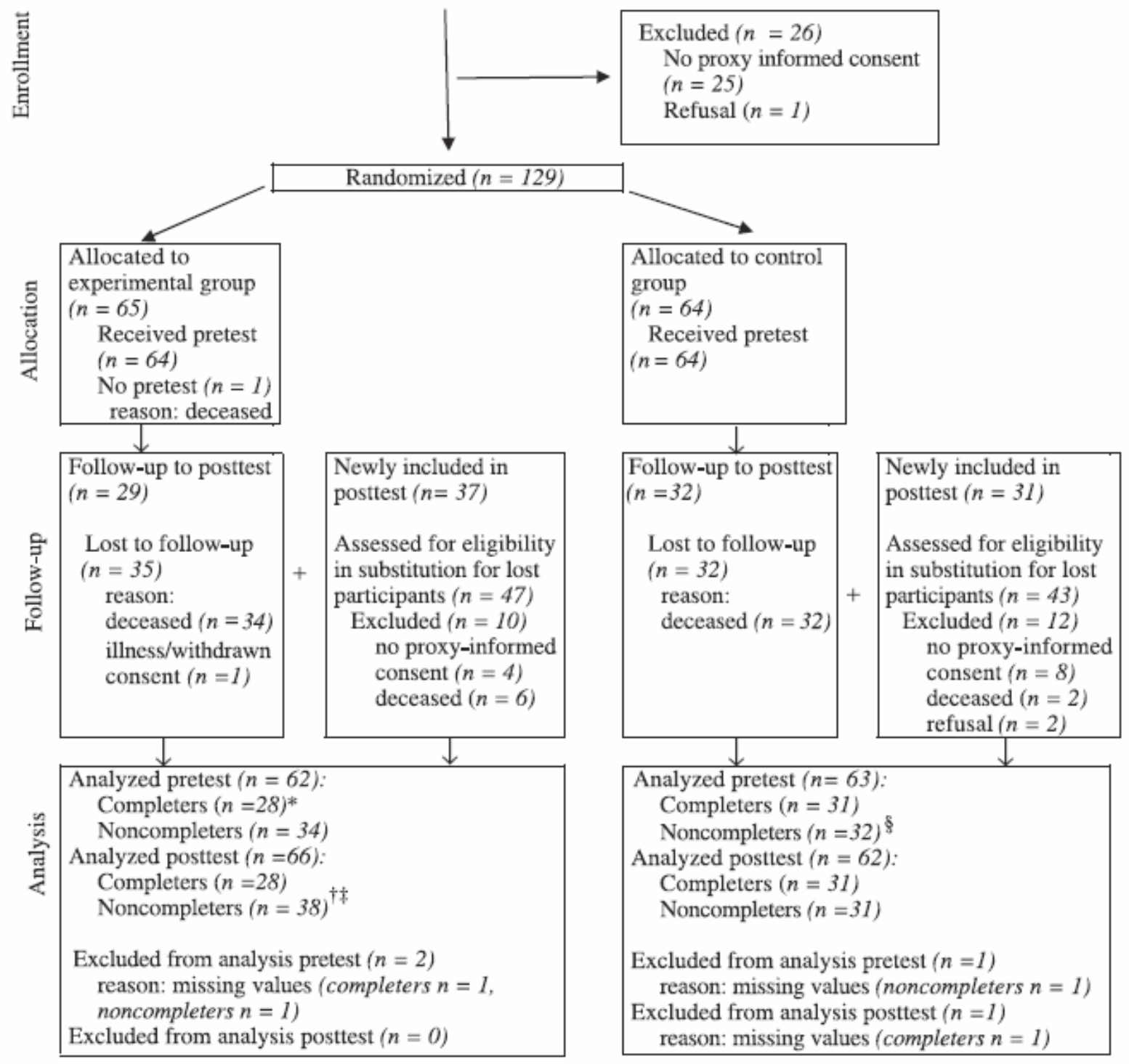

Figure 2. Flow chart of the trial.

*Video observations $(\mathrm{n}=27)$. Reason: missing values $(\mathrm{n}=1)$.

Video observations: $\mathrm{n}=36$. Reason: missing values $(\mathrm{n}=2)$.

$\ddagger 37$ newly included residents +1 “completer” with missing values in pretest.

$\S_{31}$ noncompleters +1 "completer" with missing values in posttest. 


\begin{tabular}{|c|c|c|c|c|c|c|c|c|}
\hline \multirow{3}{*}{$\begin{array}{l}\text { Outcome Measure } \\
\text { (Range)* }\end{array}$} & \multicolumn{3}{|c|}{ Experimental Group } & \multicolumn{3}{|c|}{ Control Group } & \multirow{3}{*}{$\begin{array}{l}\text { Change } \\
\text { Score }^{\dagger}\end{array}$} & \multirow{3}{*}{$\begin{array}{c}\chi^{2} \\
(d f=1)\end{array}$} \\
\hline & Pretest & Posttest & \multirow[b]{2}{*}{ Change } & Pretest & Posttest & \multirow[b]{2}{*}{ Change } & & \\
\hline & \multicolumn{2}{|c|}{ Mean $^{\ddagger} \pm$ SE } & & \multicolumn{2}{|c|}{$\operatorname{Mean}^{\ddagger} \pm \mathrm{SE}$} & & & \\
\hline \multicolumn{9}{|l|}{ Behavior $^{\S}$} \\
\hline Nonsocial behavior $(0-24)$ & $13.82 \pm 0.4$ & $13.31 \pm 0.4$ & 0.51 & $13.78 \pm 0.4$ & $13.81 \pm 0.4$ & -0.03 & 0.54 & 0.54 \\
\hline Apathetic behavior $(0-18)$ & $10.98 \pm 0.3$ & $9.87 \pm 0.3$ & $1.11^{\dagger \dagger}$ & $10.48 \pm 0.3$ & $10.62 \pm 0.3$ & -0.15 & $1.26^{* *}$ & 5.16 \\
\hline Loss of consciousness $(0-21)$ & $9.14 \pm 0.4$ & $7.89 \pm 0.4$ & $1.25^{* *}$ & $8.19 \pm 0.4$ & $7.60 \pm 0.4$ & 0.60 & 0.65 & 0.75 \\
\hline Loss of decorum (0-15) & $7.72 \pm 0.4$ & $6.88 \pm 0.3$ & 0.84 & $6.60 \pm 0.4$ & $7.34 \pm 0.3$ & -0.74 & $1.58^{* *}$ & 6.22 \\
\hline Rebellious behavior $(0-15)$ & $6.09 \pm 0.3$ & $5.23 \pm 0.3$ & $0.87^{* *}$ & $5.03 \pm 0.3$ & $5.60 \pm 0.3$ & -0.57 & $1.44^{* *}$ & 5.99 \\
\hline Restless behavior $(0-15)$ & $4.42 \pm 0.3$ & $4.11 \pm 0.3$ & 0.31 & $3.66 \pm 0.3$ & $4.01 \pm 0.3$ & -0.35 & 0.66 & 1.25 \\
\hline Anxious behavior (0-18) & $4.04 \pm 0.4$ & $4.03 \pm 0.5$ & 0.02 & $3.47 \pm 0.4$ & $4.36 \pm 0.5$ & -0.89 & 0.91 & 1.70 \\
\hline \multicolumn{9}{|l|}{ Agitation\| } \\
\hline Aggressive behavior $(0-60)$ & $5.36 \pm 0.8$ & $3.53 \pm 0.7$ & 1.83 & $3.73 \pm 0.8$ & $4.93 \pm 0.7$ & -1.21 & $3.03^{* *}$ & 4.33 \\
\hline $\begin{array}{l}\text { Physically nonaggressive } \\
\text { behavior }(0-36)\end{array}$ & $3.94 \pm 0.6$ & $3.53 \pm 0.5$ & 0.41 & $4.02 \pm 0.6$ & $3.64 \pm 0.5$ & 0.38 & 0.03 & 0.00 \\
\hline $\begin{array}{l}\text { Verbally agitated } \\
\text { behavior }(0-30)\end{array}$ & $5.21 \pm 0.6$ & $5.06 \pm 0.6$ & 0.14 & $4.59 \pm 0.6$ & $5.26 \pm 0.6$ & -0.67 & 0.81 & 0.69 \\
\hline Depression" $^{\#}(0-30)$ & $8.93 \pm 0.6$ & $7.44 \pm 0.5$ & $1.48^{* *}$ & $7.22 \pm 0.6$ & $7.88 \pm 0.5$ & -0.66 & $2.14^{* * *}$ & 4.83 \\
\hline
\end{tabular}

\section{REFERENCES}

1. Wimo A, Winblad B, Aguero-Torres $\mathrm{H}$ et al. The magnitude of dementia occurrence in the world. Alzheimer Dis Assoc Disord 2003;17:63-67.

2. Buettner $\mathrm{LL}$, Lundegren $\mathrm{H}$, Lago $\mathrm{D}$ et al. Therapeutic recreation as an intervention for persons with dementia and agitation: An efficacy study. Am J Alzheimers Dis 1996;11:4-12.

3. Kitwood T. A dialectical framework for dementia. In: Woods RT, ed. Handbook of the Clinical Psychology of Ageing. Chichester: John Wiley and Sons Ltd, 1996, pp 267-282.

4. Kitwood T. Dementia Reconsidered. The Person Comes First. Buckingham: Open University Press, 1997.

5. Kitwood T. Towards a theory of dementia care: Ethics and interactions. J Clin Ethics 1998;9:2334.

6. Spaull D, Leach $C$. An evaluation of the effects of sensory stimulation with people who have dementia. Behav Cogn Psychother 1998;26:77-86.

7. Chitsey AM, Haight BK, Jones MM. Snoezelen: A multisensory environmental intervention. J Gerontol Nurs 2002;28:41-49.

8. Kok W, Peter J, Choufour J. Snoezelen. Amsterdam: Bernardus Expertisecentrum/ Fontis, 2000.

9. Bensing J. Bridging the gap. The separate worlds of evidence-based medicine and patientcentered medicine. Patient Educ Couns 2000;39:17-25.

10. Lancioni GE, Cuvo AJ, O'Reilly MF. Snoezelen: An overview of research with people with developmental disabilities and dementia. Disabil Rehabil 2002;24:175-184.

11. Chung JC, Lai CKY, Chung PMB et al. Snoezelen for dementia. Cochrane Database Syst Rev 2002;(4):CD003152.

12. Holtkamp CC, Kragt K, van Dongen MC et al. Effects of snoezelen on the behavior of demented elderly [Effecten van snoezelen op het gedrag van demente ouderen]. Tijdschr Gerontol Geriatr 1997;28:124-129.

13. Baker R, Dowling Z,Wareing LA et al. Snoezelen: Its long-term and short-term effects on older people with dementia. Br J Occup Ther 1997;60:213-218.

14. Baker R, Bell S, Baker E et al. A randomized controlled trial of the effects of multi-sensory stimulation (MSS) for people with dementia. Br J Clin Psychol 2001;40:81-96.

15. Sambandham M, Schirm V. Music as a nursing intervention for residents with Alzheimer's disease in long-term care. Geriatr Nurs 1995;16:79-83. 
16. Robichaud L, He'bert R, Desrosiers J. Efficacy of a sensory integration program in behaviors of inpatients with dementia. Am J Occup Ther 1994; 48:355-360.

17. Hogg J, Cavet J, Lambe L et al. The use of 'snoezelen' as multisensory stimulation with people with intellectual disabilities: A review of the research. Res Dev Disabil 2001;22:353-372.

18. Hoek JP, Pennix BW, Ligthart GJ et al. Health care for older persons, a country profile: The Netherlands. J Am Geriatr Soc 2000;48:214-217.

19. Diagnostic and Statistical Manual of Mental Disorders, 4th Ed. Washington, DC: American Psychiatric Association, 1994.

20. Dijkstra A. Care Dependency: An Assessment Instrument for Use in Long-term Care Facilities. Dissertation [Academisch proefschrift]. Groningen: De Regenboog, 1998.

21. Dijkstra A, Buist GA, Dassen ThW et al. The Measurement of Care Dependency with the Care Dependency Scale (CDS): A Manual [Het Meten van Zorgafhankelijkheid met de ZorgAfhankelijkheidsSchaal (ZAS): een handleiding]. Groningen: Noordelijk Centrum voor Gezondheidsvraagstukken, 1999.

22. Dijkstra A, Buist G, Moorer P et al. Construct validity of the nursing-care dependency scale. J Clin Nurs 1999b;8:380-388.

23. VanHaitsma K, Lawton MP, Kleban MH et al. Methodological aspects of the study of streams of behavior in elders with dementing illness. Alzheimer Dis Assoc Disord 1997;11:228-238.

24. Caris-Verhallen WMCM. Nurse-Patient Communication in Elderly Care. Utrecht: NIVEL, 1999.

25. Finnema EJ. Emotion-oriented Care in Dementia: A Psychosocial Approach. Dissertation. Groningen: De Regenboog, 2000.

26. Weert JCM, Kerkstra A, van Dulmen AM et al. The implementation of snoezelen in psychogeriatric care: An evaluation through the eyes of caregivers. Int J Nurs Stud 2004;41:397-409.

27. Schrijnemaekers V, van Rossum E, CandelMet al. Effects of emotion-oriented care on elderly people with cognitive impairment and behavioral problems. Int J Geriatr Psychiatry 2002;17:926937.

28. Verstraten PFJ, van Eekelen CWJM. Manual for the BIP. Dutch Behavior Observation Scale for Psychogeriatric In-patients [Handleiding voor de GIP. Gedragsobservatieschaal voor de Intramurale Psychogeriatrie]. Deventer: Van Loghum Slaterus, 1987.

29. Verstraten PF. The BIP. Fourteen observation scales for psychogeriatric behavior problems [De GIP. Veertien observatieschalen voor psychogeriatrische gedragsproblemen]. Tijdschr Gerontol Geriatr 1988;19:147-151.

30. Wee SC. Differentation Adaptation. The Basis of Integration in the Organization Among Medical Specialists in Dutch General and Academic Hospitals [Differentiatie \& Adaptatie. Het Draagvlak voor Integratie in de Organisatie onder Medisch Specialisten in Algemene en Academische Ziekenhuizen in Nederland]. Dissertation [Academisch proefschrift]. Nijmegen: SCCMvan der Wee, 2000.

31. Cohen-Mansfield J, Marx MS, Rosenthal AS. A description of agitation in a nursing home. J Gerontol 1989;44:M77-M84.

32. Cohen-Mansfield J. Instruction Manual for the Cohen-Mansfield Agitation Inventory (CMAI). Rockville, MD: The Research Institute of the Hebrew Home of Greater Washington, 1991.

33. De Jonghe JF, Kat MG. Factor structure and validity of the Dutch version of the Cohen-Mansfield Agitation Inventory (CMAI-D). J Am Geriatr Soc 1996;44:888-889.

34. Miller RJ, Snowdon J, Vaughan R. The use of the Cohen-Mansfield Inventory in the assessment of behavioral disorders in nursing homes. J Am Geriatr Soc 1995;43:546-549.

35. Alexopoulos GS, Abrams RC, Young RC et al. Cornell Scale for Depression in Dementia. Biol Psychiatry 1988;23:271-284.

36. Droe"s RM. The Dutch version of the Cornell Scale for Depression in Dementia [De Nederlandse versie van de Cornell Scale voor Depressie bij Dementie]. In: Droe"s RM, ed. Amsterdam Meeting Centers, a New Way to Support Demented People and Their Carers [Amsterdamse Ontmoetingscentra, een Nieuwe Vorm van Ondersteuning voor Dementerende Mensen en hun Verzorgers]. Amsterdam: Thesis Publishers, 1996, p. 214.

37. Baker R, Dowling Z. INTERACT. Dorset: Poole Hospital, Research and Development Support Unit, 1995.

38. Diepen E, Baillon SF, Redman J et al. A pilot study of the psychological and behavioral effects of snoezelen in dementia. Br J Occup Ther 2002;65:61-66.

39. Lawton MP. Assessing quality of life in Alzheimer disease research. Alzheimer Dis Assoc Disord 1997;11:91-99. 
40. Lawton MP, Weisman GD, Sloane P et al. Professional environmental assessment procedure for special care units for elders with dementing illness and its relationship to the therapeutic environment screening schedule. Alzheimer Dis Assoc Disord 2000;14:28-38.

41. Volicer L, Hurley AC, Camberg L. A model of psychological well-being in advanced dementia. J Ment Health Aging 1999;5:83-94.

42. Volicer L, Camberg L, Hurley AC et al. Dimensions of decreased psychological well-being in advanced dementia. Alzheimer Dis Assoc Disord 1999;13:192- 201.

43. Whaley L, Wong D. Nursing Care of Infants and Children. St. Louis: Mosby Year Book, 1987.

44. Wells DL, Dawson P, Sidani S et al. Effects of an abilities-focused program of morning care on residents who have dementia and on caregivers. J Am Geriatr Soc 2000;48:442-449.

45. Bryk AS, Raudenbusch SW. Hierarchical Linear Models. Applications and Data Management Methods. Newbury Park, CA: Sage Publications, 1992.

46. Goldstein H. Multilevel Statistical Models. New York: Halsted Press, 1995.

47. Jirovec MM, Kasno J. Predictors of self-care abilities among the institutionalized elderly. West $\mathrm{J}$ Nurs Res 1993;15:314-326.

48. De Jonghe JFM, Goedhart AW, Ooms ME et al. Negative symptoms in Alzheimer's disease: A confirmatory factor analysis. Int J Geriatr Psychiatry 2003;18:748-753. 